\title{
Toxicity of nonionic surfactants
}

\author{
K. Jahan ${ }^{1}$, S. Balzer ${ }^{2}$ \& P. Mosto ${ }^{3}$ \\ ${ }^{I}$ Professor of Civil and Environmental Engineering, Rowan University, \\ Glassboro, New Jersey, USA \\ ${ }^{2}$ Bureau of Dam Safety and Flood Control, \\ New Jersey Department of Environmental Protection, Trenton, \\ New Jersey, USA \\ ${ }^{3}$ Professor of Biological Sciences, Rowan University, \\ Glassboro, New Jersey, USA
}

\begin{abstract}
Nonionic surfactants are amphilic chemicals that enhance desorption and bioavailability by increasing solubility and dispersion of poorly soluble hydrocarbons and oils. This study was conducted to determine the toxicity of commercial nonionic surfactants by using the Microtox ${ }^{\circledR}$ Acute Toxicity test which is a rapid, simple test for toxicity. The test uses the luminescent bacterium $\mathrm{V}$. fischeri as the test organism. Five common commercial nonionic surfactants Tergitol NP-10, Triton X-100, Igepal 630, Brij 35 and Tween 40 were used in the study. Light readings were taken initially as well as at 0 minutes, 5 minutes and 10 minutes to see how the toxicity of each surfactant changed with time. Experiments were conducted to determine the five-minute $\mathrm{EC}_{50}$ values. $\mathrm{EC}_{50}$ is the effective concentration that causes a $50 \%$ decrease in light output in a 5-minute exposure period. A higher effective concentration is interpreted as a lower toxicity. The critical toxic concentration (CTC) was also determined. Toxicity of the surfactants varied according to their difference in chemical structures and branching. $\mathrm{EC}_{50}$ values were less than the $\mathrm{CTC}$ and $\mathrm{CMC}$ values of all select surfactants. Higher toxicity was shown by surfactant solutions that contained a benzene ring in comparison to the others.
\end{abstract}

Keywords: nonionic, surfactants, microtox, critical toxic concentration. 


\section{Introduction}

Nonionic surfactants are amphilic chemicals that enhance desorption and bioavailability by increasing solubility and dispersion of poorly soluble hydrocarbons and oils [1]. Because of their properties, effectiveness, economy, and ease of handling and formulating, they are widely used for emulsion polymerization and polymer stabilization in plastics and elastomers; cleaning, spinning, weaving, and finishing of textiles; wetting agents and emulsifiers in agricultural chemicals; and pulping and de-inking in the paper industry. Institutional uses of nonionic surfactants include cleaning products, commercial laundry detergents, janitorial products, and vehicle cleaners. In households, nonionic surfactants are used in laundry detergents and hard-surface cleaners [1].

Because of the widespread use of non-ionic surfactants, their discharge into the environment is of concern [2]. As such biodegradability and toxicity of these surfactants are continuously being assessed.

Toxicity is the study of "the nature of the adverse effects caused by toxic agents as well as the probability of their occurrence" [3]. Toxicity tests have been used to "assess the suitability of environmental conditions for aquatic life" [3]. Toxicity has been measured by using small crustaceans such as Daphnia magna, Ceriodaphnia dubia, fathead minnows (Pimephales promelas), and marine luminescent bacteria [3]. Several different commercial systems have been used to determine acute toxicity, such as Microtox $^{\circledR}$ [2], Toxalert ${ }^{\circledR}$ [3] and Spirotox [4]. Algal tests are also common [5]. Aerobic and anaerobic biodegradability is also another method of testing toxicity [5].

Pettersson et al [6] determined the acute toxicity to Daphnia magna for twenty six detergents and five softeners produced in Sweden. The researchers concluded that these products were relatively toxic to aquatic life. It was also concluded that both anionic and non-ionic surfactants are toxic to various aquatic organisms. Similar conclusions were also reported by Warne and Schifko [7] for 30 laundry detergent components. These authors along with Cserháti [8] confirmed that non-ionic surfactants are more toxic than the anionic surfactants. The European Community Environmental Legislation classifies the toxicity of chemicals on the basis of $\mathrm{LC}_{50} . \mathrm{LC}_{50}$ is defined as is the concentration of a chemical that kills $50 \%$ of a sample population. According to this classification all anionic surfactants are classified harmful for $\mathrm{LC}_{50}$ between $10-100 \mathrm{mg} / \mathrm{L}$ while non-ionic surfactants are toxic for $\mathrm{LC}_{50}$ between 1.0 and $10 \mathrm{mg} / \mathrm{L}$.

Most nonionic surfactants are composed of linear or nonyl-phenol alcohols or fatty acids. The hydrophilic behavior of nonionic surfactants is caused either by polymerized glycol ether or glucose units. They are almost exclusively synthesized by the addition of ethylene oxide or propylene oxide to alkylphenols (AP), fatty alcohols, fatty acids, or fatty acid amides. Different types of commercial nonionic surfactants are presented in Table 1.

APEs are nonionic surfactants made up of a branched chain ethylene oxide to produce an ethoxylate chain. The main alkylphenols used are nonylphenol (NP) and octylphenol (OP). Nonylphenol ethoxylates encompass about $80 \%$ of the 
Table 1: $\quad$ Classification of nonionic surfactants [9].

Alcohol ethoxylates (AEO)

world market, and octylphenol ethoxylates (OPEs) represent most of the rest [1]. They have been used extensively for their effectiveness, economy and ease of handling and formulating for more than forty years. Nonylphenol (NP) is a byproduct of nonionic surfactants, specifically nonylphenol ethoxylates (NPE). It has been found in freshwater and saltwater environments into which wastewater treatment effluents are discharged. NP is persistent in groundwater and in landfills under anaerobic conditions [1]. Nonylphenol has also been found to mimic estrogen. The possible effects of estrogen-mimicking compounds on humans include breast cancer and early puberty in women. Possible effects in men are testicular cancer and low sperm count [10]. NP and NPE have been found to be acutely toxic to aquatic organisms. In one study, four species of Australian tadpoles and two exotic frogs were exposed to NPE and alcohol alkoxylate. All six species exhibited decreased activity and reduced reaction to external stimuli [11]. Hernando et al [12] reported that 4-nonylphenol is very toxic to aquatic organisms with an $\mathrm{EC}_{50}$ at 30 minutes of $0.48 \mathrm{mg} / \mathrm{L}$. Octylphenolethoxylates (OPE) and octylphenol (OP) a byproduct of OPE biodegradation are also known to exhibit toxicity [1].

This study attempted to determine the toxicity of five common industrial nonionic surfactants, Tergitol NP-10, Triton X-100, Igepal 630, Brij 35 and Tween 40. Nonionic surfactants are characterized by higher hydrocarbon solubilizing power, weaker adsorption to charged sites, less toxicity to bacteria, poor foaming properties and compatibility with other types of surfactants. Table 2 indicates the type and structure of the select surfactants provided by the manufacturer. 
Different types of surfactant structures were selected to study their impact on toxicity. Five different classes of nonionic surfactants were selected to include a wide variety for testing.

Table 2: $\quad$ Select nonionic surfactants for this study.

\begin{tabular}{ccc}
\hline Surfactant & Type & Molecular Structure \\
\hline Tergitol & Nonylphenol ethoxylates & $\mathrm{C}_{9} \mathrm{H}_{19}\left(\mathrm{C}_{6} \mathrm{H}_{4}\right) \mathrm{O}\left(\mathrm{CH}_{2} \mathrm{CH}_{2} \mathrm{O}\right)_{10} \mathrm{H}$ \\
NP-10 & Octylphenol & \\
Triton & $\mathrm{C}_{8} \mathrm{H}_{17}-\mathrm{C}_{6} \mathrm{H}_{4}-\left(\mathrm{OCH}_{2} \mathrm{CH}_{2}\right)_{8} \mathrm{OH}$ \\
X-114 & Octylphenyl-polyethylene glycol & $\left(\mathrm{C}_{2} \mathrm{H}_{4} \mathrm{O}\right)_{9} \mathrm{C}_{14} \mathrm{H}_{22} \mathrm{O}$ \\
Igepal & Polyoxyethyleneglycol dodecyl \\
630 & ether & $\mathrm{C}_{12} \mathrm{H}_{25}\left(\mathrm{CH}_{2} \mathrm{CH}_{2} \mathrm{O}\right)_{23} \mathrm{OH}$ \\
Brij & Polyoxyethylenate & \\
35 & sorbitol ester & $\left.\mathrm{C}_{16} \mathrm{H}_{34} \mathrm{O}_{2} \mathrm{C}_{6} \mathrm{H}_{10} \mathrm{O}_{4} \mathrm{CH}_{2} \mathrm{CH}_{2} \mathrm{O}\right)_{20}$ \\
Tween & Po & \\
40 & & \\
\hline
\end{tabular}

\section{Materials and methods}

All surfactants were obtained from Sigma Chemicals, St. Louis, MO, USA. Surfactants were used without further purification, as they would be in any largescale application. Stock surfactant solutions were prepared in deionized water purified by a Millipore Milli-Q Plus water system. A surface tensiometer (VWR, Bridgeport, $\mathrm{NJ}$ ) was used to determine the critical micelle concentrations (CMC) of the surfactants. The CMC occurs at the surfactant concentration beyond which there is no further change in surface tension of the surfactant solution. The CMC is also defined as the concentration of surfactants above which micelles are spontaneously formed. Upon introduction of surfactants into a system they initially partition into the interface, reducing the system free energy by a) lowering the energy of the interface and b) by removing the hydrophobic parts of the surfactant from contacts with water. Subsequently, when the surface coverage by the surfactants increases and the surface free energy (surface tension) has decreased, the surfactants start aggregating into micelles, thus again decreasing the system free energy by decreasing the contact area of hydrophobic parts of the surfactant with water. Upon reaching CMC, any further addition of surfactants will just increase the number of micelles.

All surfactants were tested on the luminescent bacteria Vibrio Fisceri for toxicity using the Microtox ${ }^{\circledR}$ Model 500 Toxicity Analyzer System. All materials for the Microtox ${ }^{\circledR}$ test were obtained from Azur Environmental, Carlsbad, CA, USA. A total of 8 replicates were conducted for each test with the select surfactants. Data was analyzed by first determining $\Gamma$ (Gamma) at a specific time, in this case five minutes. $\Gamma$ is the ratio of light lost to the light remaining 
and is assumed to be proportional to toxicity. $\log \Gamma$ was then graphed versus surfactant concentration. The toxicity endpoint was then obtained from this plot as the effective concentration $\left(\mathrm{EC}_{50}\right)$ that causes a $50 \%$ decrease in light output in a five minute exposure period (5-min $\left.\mathrm{EC}_{50}\right)$. A higher effective concentration is interpreted as lower toxicity. Hinwood and McCormick [13] have described the details of the experimental procedure. These authors also indicated that $\log \Gamma$ increases with concentration only up to a certain point beyond which no further increase can be observed. The concentration at this point is termed as the Critical Toxicity Concentration (CTC) and the proportionality between $\log \Gamma$ and concentration no longer holds beyond this point. The curve plateaus beyond this point [2].

\section{Results and discussion}

Surface tension measurements at various surfactant concentrations were determined and plotted to obtain $\mathrm{CMC}$ values. A wide range of surfactant concentrations were prepared to determine the $\mathrm{CMC}$ values.

A typical CMC plot for the select surfactants is presented in Figure 1. The CMC for Tergitol NP-10 was determined to be $40 \mathrm{mg} / \mathrm{L}$ which is similar to that reported by the manufacturer.

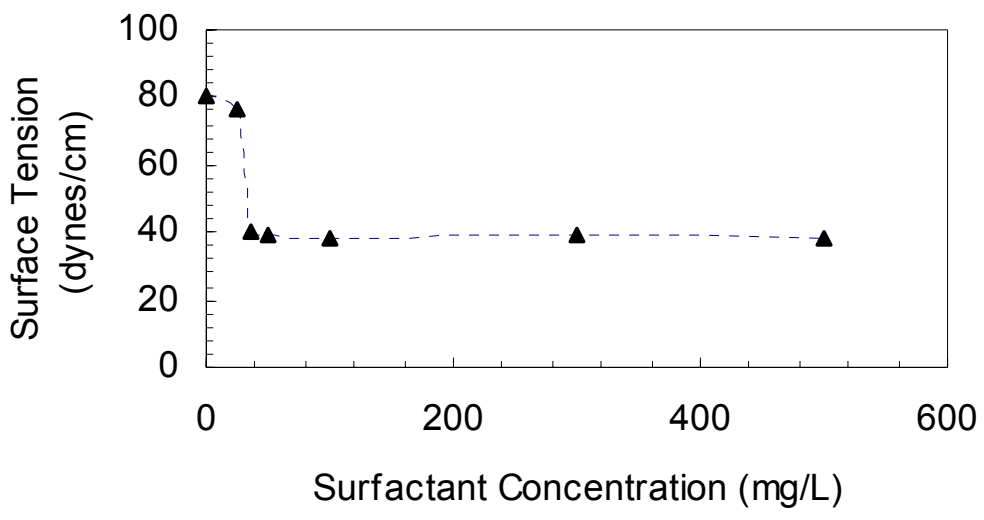

Figure 1: $\quad$ CMC determination for Tergitol NP-10.

Sample results for the Microtox experiments with Triton X-114 are presented in Figure 2 where $\log \Gamma$ has been plotted against the surfactant concentration. It is evident from the figure that the CTC for Triton X-114 is around $65 \mathrm{mg} / \mathrm{L}$. The $\mathrm{EC}_{50}$ for this surfactant was calculated to be $6.88 \mathrm{mg} / \mathrm{L}$ at five minutes. As such the $\mathrm{EC}_{50}$ was lower than the CTC and CMC of the surfactant.

The five minute $\mathrm{EC}_{50}$ along with the associated $95 \%$ confidence limit, $\mathrm{CMC}$, CTC, molecular weight (MW) and the hydrophile-lipophilic balance number (HLB) are provided for all surfactants in Table 3. 


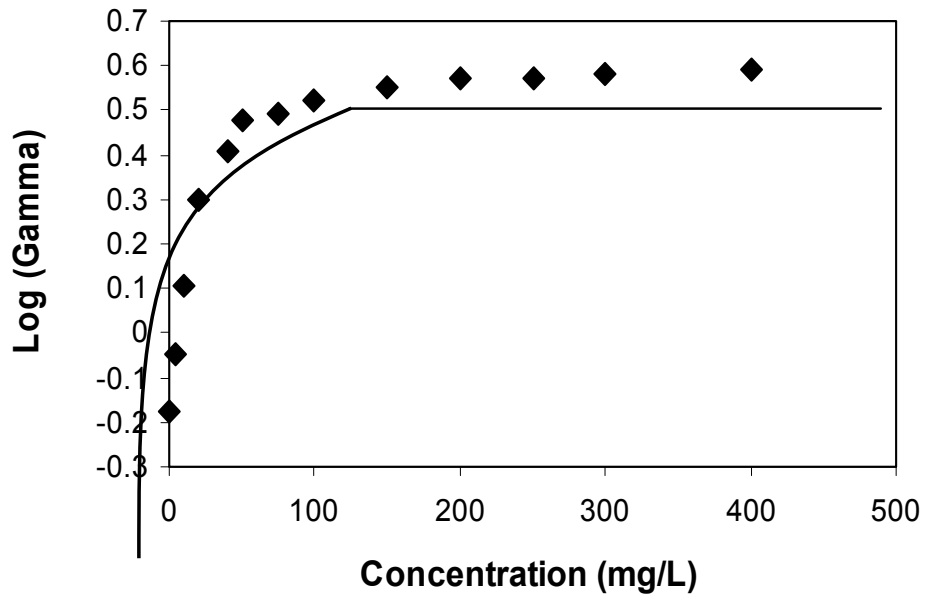

Figure 2: $\quad$ Determination of $\mathrm{EC}_{50}$ and CTC values for Triton X-114.

Table 3: $\quad \mathrm{EC}_{50}, \mathrm{CTC}$ and $\mathrm{CMC}$ values obtained for the select surfactants.

\begin{tabular}{|c|c|c|c|c|c|c|}
\hline Surfactant & $\begin{array}{l}\mathrm{MW}^{1} \\
\mathrm{~g} / \mathrm{mol}\end{array}$ & $\mathrm{HLB}^{2}$ & $\begin{array}{l}\mathrm{EC}_{50} \\
\mathrm{mg} / \mathrm{L}\end{array}$ & $\begin{array}{l}\text { Confidence } \\
\text { Limits }\end{array}$ & $\begin{array}{l}\mathrm{CTC} \\
\mathrm{mg} / \mathrm{L} \\
\end{array}$ & $\begin{array}{l}\mathrm{CMC} \\
\mathrm{mg} / \mathrm{L}\end{array}$ \\
\hline Tergitol NP-10 & 652 & 13.2 & 4.68 & $3.08-6.28$ & 35 & 55 \\
\hline Triton X-114 & 536 & 12.9 & 6.88 & $2.55-11.21$ & 65 & 110 \\
\hline Igepal 630 & 603 & 13.0 & 51.2 & $40.6-61.8$ & 38 & 48.3 \\
\hline Brij 35 & 1200 & 16.9 & 10.34 & $8.04-12.64$ & 42 & 74 \\
\hline Tween 40 & 1283 & 15.6 & 15.67 & $10.47-20.87$ & 21 & 30 \\
\hline$\overline{\text { Surfe }}$ & $\begin{array}{l}\mathrm{MW}^{1} \\
\mathrm{~g} / \mathrm{mol}\end{array}$ & $\mathrm{HLB}^{2}$ & $\begin{array}{l}\mathrm{EC}_{50} \\
\mathrm{mg} / \mathrm{L}\end{array}$ & $\begin{array}{l}\text { Confidence } \\
\text { Limits }\end{array}$ & $\begin{array}{l}\mathrm{CTC} \\
\mathrm{mg} / \mathrm{L}\end{array}$ & $\begin{array}{l}\mathrm{CMC} \\
\mathrm{mg} / \mathrm{L}\end{array}$ \\
\hline Tergitol NP-10 & 652 & 13.2 & 4.68 & $3.08-6.28$ & 35 & 55 \\
\hline Triton X-114 & 536 & 12.9 & 6.88 & $2.55-11.21$ & 65 & 110 \\
\hline Igepal 630 & 603 & 13.0 & 51.2 & $40.6-61.8$ & 38 & 48.3 \\
\hline Brij 35 & 1200 & 16.9 & 10.34 & $8.04-12.64$ & 42 & 74 \\
\hline Tween 40 & 1283 & 15.6 & 15.67 & $10.47-20.87$ & 21 & 30 \\
\hline
\end{tabular}

${ }^{1} \mathrm{MW}$ - Molecular Weight ${ }^{2}$ HLB - Hydrophilic/Lipophilic Balance.

The HLB number indicates the measure of the degree to which it is hydrophilic or lipophilic, as determined by calculating values for the different regions of the molecule [14]. An HLB value of 0 corresponds to a completely 
hydrophobic molecule, and a value of 20 would correspond to a molecule made up completely of hydrophilic components. The HLB value can be used to predict the surfactant properties of a molecule:

- A value from 3 to 6 indicates a W/O emulsifier

- A value from 7 to 9 indicates a wetting agent

- A value from 8 to 12 indicates an $\mathrm{O} / \mathrm{W}$ emulsifier

- A value from 12 to 15 is typical of detergents

- A value of 15 to 20 indicates a solubiliser or hydrotrope

In our case all selected surfactants have HLB numbers typical for detergents except Brij 35 and Tween 40. It is apparent from Table 3 that Tween 40 had the lowest toxicity of the select surfactants. In a study conducted by Lee et al [15] the researchers also observed that Tween 40 was less toxic than Brij 35 to strain P. Putida ATCC 17484.

Helenius and Simons [16] and Dorn et al [17] indicated that the Triton surfactants can solubilise the lipid bilayer membrane by integration into the cell membrane while the Tween series can also be incorporated into bacterial membranes these products are ineffective in solubilising membrane lipids.
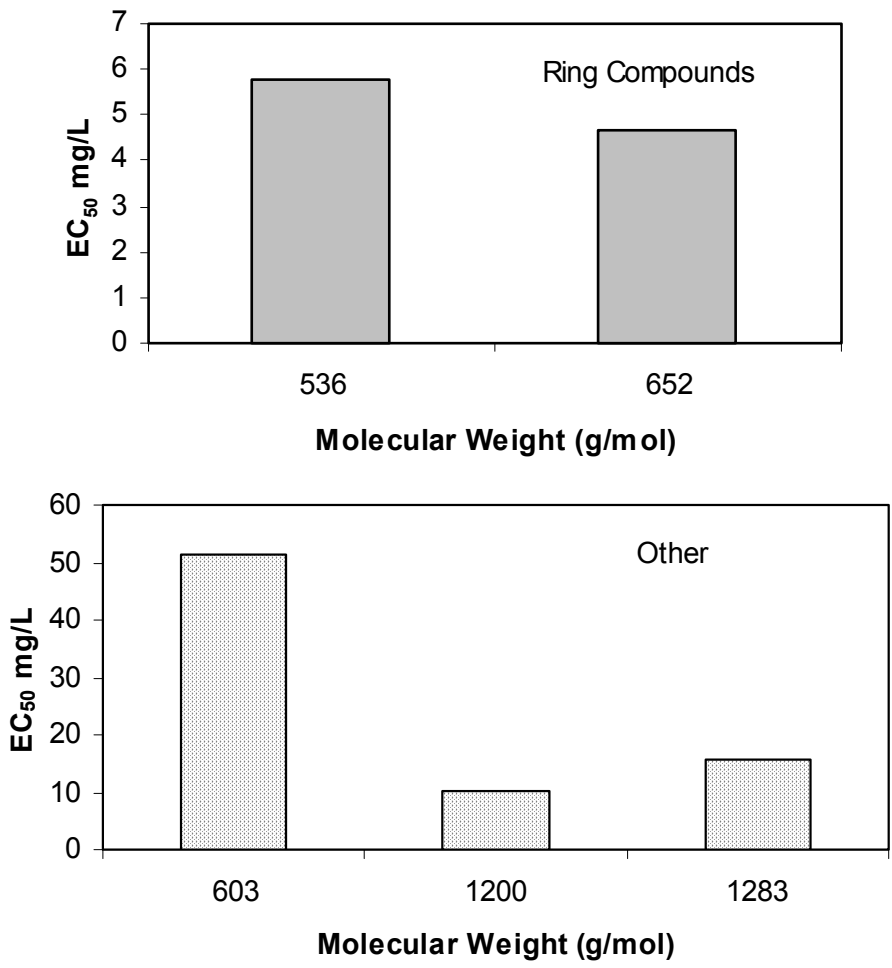

Figure 3: Relation between molecular weight and toxicity for select surfactants. 
Liwarska-Bizukojc et al [3] also indicated that non-ionic surfactants were more toxic than the anionic surfactants to three aquatic organisms: gastropod Physa acuta, crustacean Artemia salina and alga Rapidocelis subcapitata. These authors reported that the toxicity increased as the molecular weight of the surfactant increased. Morrall et al [18, 19] also found a relationship between toxicity and molecular weights of surfactants. This phenomenon was exhibited in our studies too when the surfactants were grouped according to their structures. The relation between molecular weight and toxicity in terms of EC50 was investigated and is presented in Figure 3.

Ernst and Arditti [20] also indicated that physical properties of surfactants are a principal cause of the toxic effects of these detergents in HeLa cells. These researchers observed that the toxicity of nonionics generally decreased inversely with increasing hydrophilic chain length and increased with increasing size of the lipophile. Lethal levels of the surfactants coincided with surface tension reduction of the media to 45 dynes $\mathrm{cm}^{-1}$ or below. Surface tensions of non-toxic concentrations were substantially higher than those for toxic levels. Non-toxic doses were, therefore, below the critical micelle concentration of the surfactants evaluated.

High toxicity was shown by surfactant solutions that contained a benzene ring and branched aliphatic chain in the molecule and solutions with molecules containing short polyoxyethylene chains. CTC values were consistently lower than the CMC values for all surfactants although they are of the same magnitude. This was also observed by Sherrard et al [2]. These authors indicated that an association between surface tension and toxicity of the surfactant existed and they concluded that the non-micellar molecules produce a concentration-related toxic response.

\section{Conclusions}

Microtox ${ }^{\circledR}$ is a rapid, simple test for toxicity. However solution preparation and proper pipetting techniques are instrumental to the success of the test results. Five different non-ionic surfactants were tested for toxicity using the Microtox ${ }^{\circledR}$ test. High toxicity was shown by surfactant solutions that contained a benzene ring and branched aliphatic chain in the molecule and solutions with molecules containing short polyoxyethylene chains. CTC values were consistently lower than the CMC values for all surfactants although they are of the same magnitude. The $\mathrm{EC}_{50}$ values of all the surfactants are below $100 \mathrm{mg} / \mathrm{L}$ indicating that they all have some level of toxicity. This data is extremely important for impacts on aquatic life from discharge of detergents. It provides valuable information on selection of surfactants in critical applications in industry and also emphasizes the importance of removing detergent like substances from wastewater prior to discharge to aquatic systems.

\section{References}

[1] Maguire R.J. Review of the persistence of nonylphenol and nonylphenol ethoxylates in aquatic environments. Water Qual. Res. J. 34(1), pp. 37-78, 1999. 
[2] Sherrard K.B., Marriott P.J., McCormick M.J. \& Millington K. A limitation of the Microtox ${ }^{\circledR}$ test for toxicity measurements of nonionic surfactants. Environ. Tox. Chem., 15 (7), pp. 1034-1037, 1996.

[3] Liwarska-Bizukojc, E., Miksch, K., Malachowska-Jutsz, A. \& Kalka, J., Acute toxicity and genotoxicity of five selected anionic and nonionic surfactants. Chemosphere, 58, pp. 1249-1253, 2005.

[4] Nałęcz-Jawecki, G., Rudz, B. \& Sawicki, J., Evaluation of toxicity of medical devices using Spirotox and Microtox tests, J. Biomed. Mat. Res., 35, pp. 101-105, 1997.

[5] García, M.T., Campos, E, \& Ribosa, I., Biodegradability and ecotoxicity of amine oxide based surfactants. Chemosphere, 69, pp. 1574-1578, 2007.

[6] Pettersson, A., Adamsson, M. \& Dave, G., Toxicity and detoxification of Swedish detergents and softener products, Chemosphere 41, pp. 16111620, 2000.

[7] Warne, M. St. J. \& Schifko, A.D. Toxicity of laundry detergent components to a freshwater cladoceran and their contribution to detergent toxicity, Ecotoxicol. Environ. Saf. 44, pp. 196-206, 1999.

[8] Cserháti, T., Alkyl Ethoxylated and Alkylphenol Ethoxylated Nonionic Surfactants: Interaction with Bioactive Compounds and Biological Effects, Environmental Health Perspectives, 103, pp. 358-364, 1995.

[9] http://www.fz-juelich.de/icg/icg-3/datapool/page/455/Thiele_01_07_07.pdf

[10] Larsson, D.G.J., Hällman, H., \& Förlin, L. More male fish embryos near a pulp mill. Environ. Tox. and Chem. 19, pp. 2911-2917, 2000.

[11] Mann R.M. and Bidwell J.R. The acute toxicity of agricultural surfactants to the tadpoles of four Australian and two exotic frogs. Environ. Pollution 114, pp. 195-205, 2000.

[12] Hernando, M.D., De Vettori S., Martínez Bueno M.J. \& Fernández-Alba, A.R. Toxicity evaluation with Vibrio fischeri test of organic chemicals used in aquaculture, Chemosphere, 68(4) pp., 724-730, 2007.

[13] Hinwood, A.L. \& McCormick, M.J. The effect of ionic solutes on EC50 values measured using the Microtox test. Toxic Assess., 2, pp. 449-461, 1987.

[14] Rosen, M.J. Surfactants and Interfacial Phenomena, John Wiley \& Sons, 1989.

[15] Lee, H.J., Lee, M.W., Lee, D. S., Woo, S.H. and Park, J.M., Estimation of direct contact fraction for phenanthrene in surfactant solutions by toxicity measurement, J. Biotech., 131, pp. 448-457, 2007.

[16] Helenius, A. \& Simons, K., Solubilization of membranes by detergents. Biochim. Biophys. Acta., 415, pp. 29-79, 1975.

[17] Dorn, P. B., Salanitro, J. P., Evans, S. H. \& Kravetz, L. Assessing the aquatic hazard of some branched and linear nonionic surfactants by biodegradation and toxicity Environmental Toxicology and Chemistry, 12(10), pp. 1751-1762, 1993.

[18] Morrall, S.W., Eckhoff, W.S., Evans, A., Cano, M.L., Dunphy, J.C.\& McAvoy, D.C. Removal of alcohol ethoxylates and environmental exposure 
determination in the United States. Ecotoxicol. Environ. Saf. 64, pp. 381-389, 2006.

[19] Morrall, D.D., Belanger, S.E. \& Dunphy, J.C., Acute and chronic toxicity structure-activity relationships for alcohol ethoxylates, Ecotoxicol. Environ. Saf. 56, pp. 381-389, 2003.

[20] Ernst, R. \& Arditti J., Biological effects of surfactants: Effects of nonionics and amphoterics on HeLa cells, Toxicology, 15(3): pp. 233-242, 1980. 